Volume 3 Issue 1 (2019) Pages 30 - 38

Jurnal Obsesi : Jurnal Pendidikan Anak Usia Dini

DOI: $10.31004 /$ obsesi.v3i1.132

\title{
Konsep Pendidikan Hafidz Qur'an pada Anak Usia Dini
}

\author{
Fajriyatul Islamiah $^{1 凶}$, Lara Fridani $^{2}$, Asep Supena ${ }^{3}$ \\ Pascasarjana Universitas Negeri Jakarta, Indonesia
}

\begin{abstract}
This study aims to provide a new perspective and paradigm for the community about the concept of the Quranic hafidz education in early childhood. This study uses a case study qualitative method. Data collection techniques are carried out through interviews and observations. Interviews and observations were made to look more deeply at learning and experiences applied by parents and the life side of children who memorized the Qur'an early on. The subjects of this study were parents from Hilya Qonita, the first winner of the 2013 RCTI Indonesia Hafidz Program. The results showed that early childhood was able to memorize the Al-Qur'an 30 juz when stimulated by parents from infancy even in the womb. Parents' role and role models greatly determine the success of children in memorizing the Qur'an. The results of this study provide a new perspective that the Al-Qur'an provides blessings for parents and children. Children who take precedence with the Qur'an are easier to acquire other sciences.
\end{abstract}

Keywords: quranic education, quran memorizing, early childhood

\begin{abstract}
Abstrak
Penelitian ini bertujuan untuk memberikan perspektif dan paradigma baru bagi masyarakat tentang konsep pendidikan hafidz Qur'an pada anak usia dini. Penelitian ini menggunakan metode kualitatif studi kasus. Teknik pengumpulan data dilakukan melalui wawancara dan observasi. Wawancara dan observasi dilakukan untuk meninjau lebih dalam tentang pembelajaran dan pengalaman yang diterapkan oleh orangtua serta sisi kehidupan anak yang menghafal Al-Qur'an sejak dini. Subyek penelitian ini adalah orang tua dari Hilya Qonita, juara 1 program hafidz Indonesia RCTI 2013. Hasil penelitian menunjukkan bahwa anak usia dini mampu untuk menghafal Al-Qur'an 30 juz apabila diberikan stimulasi oleh orang tua sejak bayi bahkan sejak dalam kandungan. Peran dan teladan orang tua sangat menentukan keberhasilan anak dalam menghafal Al-Qur'an. Hasil penelitian ini memberikan perspektif baru bahwa Al-Qur'an memberikan keberkahan bagi orang tua dan anak. Anak yang didahulukan dengan ilmu Al-Qur'an lebih mudah untuk menguasai ilmu lainnya.
\end{abstract}

Kata Kunci: pendidikan Al-Qur'an, hafidz Qur'an, anak usia dini

@ Jurnal Obsesi Prodi PG-PAUD FIP UPTT 2019

$\triangle$ Corresponding author :

Address : Jalan Gorda No.12 Lubang Buaya, Jakarta Timur

Email : fajriya@hotmail.com

ISSN 2356-1327 (Media Cetak)

ISSN 2549-8959 (Media Online 


\section{PENDAHULUAN}

Anak usia dini berada pada tahap golden age periode kehidupan manusia. Pada tahap emas ini, para pendidik khususnya orang tua perlu memberikan stimulasi dan pendidikan terbaik untuk tumbuh kembang anak.

Pada umumnya, orang tua menyekolahkan anak mereka di lembaga pendidikan anak usia dini dengan tujuan optimalisasi diri dan bakat anak. (Yani \& Indrawati, 2014). Namun, di sisi lain ada orang tua yang memutuskan untuk tidak menyekolahkan anak mereka di lembaga PAUD. (Eka Widi Susanti, Adelina Hasyim, 2016). Hal ini menjadi sebuah keunikan tersendiri, apalagi stimulasi dan pendidikan yang diberikan oleh orang tua tersebut berawal dari Al-Qur'an. Pendidikan Al-Qur'an yang ditanamkan oleh orang tua sejak usia dini menjadi sesuatu yang unik dalam isu pendidikan anak usia dini.

Al-Qur'an adalah pedoman umat muslim dalam menjalani kehidupan. Sebagaimana dalam hadits riwayat Bukhari nomor 4639, Manusia terbaik ialah yang belajar dan mengajarkan Al-Qur'an. (Nawawi, 2010). Hadits tersebut menjelaskan bahwa manusia dianjurkan untuk mempelajari Al-Qur'an kemudian mengajarkannya untuk bisa menjadi manusia terbaik di sisi Allah. Kegiatan mempelajari Al-Qur'an bukan hanya dilakukan oleh orang dewasa, akan tetapi oleh semua kalangan usia bahkan anak usia dini. Anak perlu dikenalkan dengan AlQur'an sejak dini, sebab Al-Qur'an adalah pedoman dasarnya kelak dalam menjalani kehidupan. Untuk menjaga kelestarian dan kemurnian Al-Qur'an, maka perlu dimunculkannya para penghafal Al-Qur'an.

Para penghafal Al-Qur'an mulai tersebar di seluruh penjuru dunia dengan usia yang beragam, mulai dari usia dini hingga dewasa. Upaya untuk membiasakan menghafal Al-Qur'an sejak dini merupakan suatu tantangan sekaligus hal yang sangat mungkin dicapai. Hal ini diyakini karena anak usia dini sedang dalam masa eksplorasi ragam kemampuan dan potensi anak (Papalia, Olds, \& Feldman, 2009). Orang tua dengan bangga mengunggah kemampuan anaknya dalam menghafalkan surat-surat Al-Qur'an di media sosial maupun ajang pencarian Hafidzh Cilik. Salah satunya ialah program pencarian hafidzh cilik di televisi nasional seperti Hafiz Indonesia RCTI

Salah satu contoh keluarga yang mengajarkan anak untuk menghafal AlQur'an adalah orang tua dari Hilya Qonita, juara 1 program Hafidz Indonesia RCTI 2013. Orang tua Hilya berperan sebagai guru utama yang mengajarkan langsung anaknya untuk menghafal Al-Qur'an sejak dini tanpa melibatkan lembaga lain penyedia pembelajaran menghafal AlQur'an. Pendidikan yang ditanamkan langsung oleh orang tua memberikan pengalaman yang berbeda pada anak. Pengalaman tersebut diperoleh di rumah yang merupakan sekolah utama anak untuk tumbuh dan berkembang sesuai pengasuhan orang tuanya.

Orang tua berperan dalam memfasilitasi pendidikan agama termasuk pengajaran Al-Qur'an pada anak. Anak merupakan amanah yang Allah berikan pada orang tua. Guru yang paling baik dan selalu diingat adalah ia yang paling banyak mempengaruhi anak. Dia mungkin tidak menggunakan papan tulis atau memiliki gelar sarjana, tetapi pengajarannya abadi dan perhatiannya tulus. Kenyataannya, setiap orang tua adalah seorang guru (Morisson, 2012).

Pendidikan agama khususnya AlQur'an menjadi urgensi yang perlu ditanamkan pada anak sejak dini. Orang tua harus mempersiapkan bekal dan fondasi 
dasar kebaikan di tahap usia ini. Hal ini merupakan langkah cemerlang untuk membangun bangsa dan negara yang baik di kemudian hari. Nawaz dan Jahangir (2015) menjelaskan bahwa kurangnya fondasi utama di tahap usia dini dapat menghambat perkembangan emosional, sosial, dan intelektual anak di kemudian hari (Nawaz \& Jahangir, 2015).

Anak pada masa usia dini merupakan masa yang paling tepat untuk menanamkan nilai-nilai pada anak baik untuk perkembangan intelektual, sosial, emosional, bahasa, norma, dan agama. Usia dini adalah usia emas (golden age) dimana tahap ini efektif untuk menstimulasi anak dengan unsur kebaikan. Bellieni menyatakan bahwa 1.000 hari pertama yang dimulai dari konsepsi hingga akhir tahun kedua setelah kelahiran, sangat penting bagi masa depan setiap manusia dalam aspek kesehatan, perkembangan, dan pembelajaran (Bellieni, 2016). Nabi Muhammad Shalallahu 'Alayhi Wa Sallam dalam HR. Muslim: 4803, mengatakan setiap anak terlahir dalam keadaan fitrah (Nawawi, 2010). Hal ini diyakini bagi ummat muslim bahwa setiap anak dilahirkan dalam keadaan baik dan berpotensi pada kebaikan, kemudian orang tua dan lingkungan yang menjadikan anak tetap dalam kebaikan atau keluar dari fitrah kebaikan.

Orang tua memiliki pandangan yang beragam tentang pendidikan terbaik untuk anak. Hal ini didasari oleh pengetahuan dan pengalaman setiap orang tua yang berbedabeda. Sebagian orang tua memandang bahwa penerapan stimulasi untuk anak usia dini dengan kegiatan menyenangkan seperti bermain, bernyanyi, menari, calistung, dan kegiatan lainnya adalah yang terbaik. Namun di sisi lain, terdapat orang tua yang lebih memfokuskan anak pada penerapan disiplin dan pencapaian tertentu. Dalam penelitian ini yang dilakukan oleh orangtua
Hilya yang memfokuskan anaknya melalui pembiasaan untuk menghafal Al-Qur'an sejak usia dini.

\section{METODOLOGI}

Metode yang digunakan dalam penelitian ini yaitu metode kualitatif studi kasus dengan pendekatan deskriptif analisis. Pendekatan ini dipilih karena penelitian ini berusaha memaparkan dan menafsirkan gambaran suatu kejadian yang memusatkan perhatian pada masalahmasalah aktual sebagaimana adanya pada waktu penelitian dilakukan. Pendekatan ini peneliti menggunakan pembahasan yang berkaitan dengan $5 \mathrm{w}$ dan $1 \mathrm{~h}$ (apa, kenapa, kapan, siapa, dimana dan bagaimana), dalam penelitian ini data yang dikumpulkan berdasarkan interview guide (petunjuk wawancara) dan dokumen yang ada kaitannya dengan penelitian ini, penelitian ini hanya memberikan gambaran yang terjadi dalam lapangan penelitian, namun dengan tidak menguji hipotesisnya (Nazir, 2009). Subyek penelitian ini adalah orang tua dari Hilya Qonita "Juara 1 Finalis Program Hafidz Indonesia RCTI 2013" yang telah menghafal Al-Qur'an $30 \mathrm{Juz}$ di usia dini bersama orang tuanya. Tempat dan waktu penelitian ini dilakukan di kediaman subyek penelitian di Jakarta Barat sejak bulan September hingga November 2018.

\section{HASIL DAN PEMBAHASAN}

Subyek merupakan seorang perempuan yang memiliki tiga orang anak, dua diantaranya penghafal Al-Qur'an. Satu dari dua anak penghafal Al-Qur' an tersebut bernama Hilya Qonita, juara 1 program Hafidz Indonesia RCTI 2013. Subyek dan keluarga memiliki tekad yang kuat untuk menjadikan keluarga mereka sebagai ahlul Qur'an yaitu orang-orang yang senantiasa dekat, cinta, ahli dalam Al-Qur'an. Subyek menerapkan kecintaannya terhadap Al- 
Qur'an dimulai dari diri sendiri dan pasangannya yang memiliki latar belakang sebagai guru Al-Qur'an. Hal ini sebagaimana firman Allah dalam QS. AlFurqon ayat 74 yang artinya "Wahai Rabb kami, karuniakanlah pada kami dan keturunan kami serta istri-istri kami penyejuk mata kami. Jadikanlah pula kami sebagai imam bagi orang-orang yang bertakwa" (Agama, 2007). Hal ini memberikan gambaran bahwa penyejuk hati dimulai dari pasangan kemudian keturunan. Subyek dan pasangan memang memiliki kesamaan latar belakang dalam memandang pentingnya Al-Qur'an dan ingin menjadikan keturunannya paham dan dekat dengan Al-Qur'an.

Berdasarkan penelitian yang
dilakukan, pola pendidikan yang
diterapkan oleh subyek adalah meneladani pola pendidikan Rasulullah SAW dan para ulama terdahulu. Mereka mengajarkan AlQur'an terlebih dahulu sebelum mengajarkan ilmu lain lainnya. Bagi subyek dan keluarga, pendidikan Al-Qur'an harus didahulukan sebelum memperoleh pendidikan lainnya. Mereka meyakini bahwa Al-Qur'an sudah mencakup segala ilmu yang ada. Dan mereka meyakini bahwa dengan mempelajari Al-Qur'an di awal usia anak-anaknya, maka keberkahan Al-Qur'an akan mempengaruhi anak untuk mudah dalam mempelajari ilmu lain. Hal ini dibuktikan bahwa Hilya tidak diajarkan calistung secara khusus oleh subyek, namun Hilya dengan mudah bisa membaca dan berhitung dengan cepat, bahkan membaca menjadi salah satu dari hobi Hilya hingga saat ini. Hilya pun memiliki perilaku yang sopan, santun, lembut, dan pintar walau sedikit pemalu. Sifat-sifat positif ini diyakini oleh subyek dan keluarga sebagai keberkahan Al-Qur'an. Ilmu Al-Qur'an yang menuntun Hilya dan anak-anak subyek lainnya memiliki sifat dan perilaku positif. Berdasarkan penelitian
Nawaz \& Jahangir (2015) menjelaskan bahwa kurangnya fondasi utama di tahap usia dini dapat menghambat perkembangan emosional, sosial, dan intelektual anak di kemudian hari (Nawaz \& Jahangir, 2015). Subyek meyakini bahwa pondasi utama anak adalah pendidikan agama melalui AlQur'an. Pondasi utama ini yang menuntun anak untuk cakap dalam emosional, sosial, dan intelektual anak di masa depan.

Mereka mendalami dan meyakini perkataan Rasulullah bahwa Al-Qur'an yang ditanamkan ke bayi itu mengalir ke dalam darah daging mereka, dan memastikan mereka bisa tumbuh terus dalam kebaikan. Hal tersebut menjadi alasan kuat bagi subyek dan keluarga untuk menerapkan pendidikan Al-Qur'an untuk anak di usia dini.

Usia dini merupakan masa yang tepat bagi subyek untuk memberikan stimulasi terbaik melalui Al-Qur'an. Bellieni menyatakan bahwa 1.000 hari pertama yang dimulai dari konsepsi hingga akhir tahun kedua setelah kelahiran sangat penting bagi masa depan setiap manusia dalam aspek kesehatan, perkembangan, dan pembelajaran (Bellieni, 2016). Urgensi usia dini ini menjadi motivasi subyek untuk membangun pondasi yang kuat dalam menanamkan kecintaan Al-Qur'an pada anak-anaknya. Penerapan pendidikan hafidz Qur'an ini dilakukan murni di rumah subyek, tanpa lembaga dan sekolah maupun guru bantuan lain yang berkontribusi di dalamnya. Hanya suami subyek yang membantu dalam mengulang (muroja'ah) kembali hafalan Al-Qur'an Hilya ketika subyek sedang melakukan aktifitas domestik di rumahnya.

Tujuan utama subyek menerapkan pendidikan hafidz Qur'an pada anak sejak dini diawali dengan inspirasi dari suami. Suami subyek memberikan motivasi bahwa orang tua harus mengajarkan Al-Qur'an pada anak, sebab itu adalah kewajiban bagi 
orang tua menurut sudut pandang agama Islam. Motivasi lainnya ialah subyek ingin menginspirasi banyak orang sehingga para orang tua lain mengikuti jejaknya dengan mencetak generasi-generasi penghafal AlQur'an.

\section{Strategi Pendidikan Hafidz Qur'an pada} Anak Usia Dini

\section{Pendidikan Al-Qur'an dalam \\ Kandungan}

Pendidikan Al-Qur'an dimulai sejak subyek positif hamil. Semenjak itu, subyek terus membacakan Al-Qur'an pada janin yang ada dalam kandungannya satu hari satu juz, sehingga setiap bulannya subyek khatam Al-Qur'an dan janin mendengar keseluruhan Al-Qur'an.

Subyek meyakini bahwa hal ini memberikan pengaruh yang positif pada janin. Penelitian sebelumnya menjelaskan bahwa wanita hamil yang membaca atau mendengarkan Al-Qur'an dapat memberikan dampak baik pada janin atau bayi di rahim mereka yaitu mempengaruhi Intellegent Quotient (IQ), Emosional Quotient (EQ), dan Spiritual Quotient (SQ) pada bayi (Suciati, 2015). Menurut penelitian ilmiah terbaru, anak-anak dapat dididik sejak dalam kandungan, sebab otak dan indera pendengaran anak sudah mulai berkembang, mereka dapat merasakan apa yang terjadi di luar kehidupan mereka, sementara yang mempengaruhi otak dan indera pendengaran bayi di dalam kandungan antara lain emosi dan jiwa ibu, serta rangsangan suara yang terjadi di sekitar ibu.

\section{Stimulasi Al-Qur'an Pada Masa Bayi}

Subyek memperdengarkan murottal Al-Qur'an pada bayi secara konsisten. Hal itu dilakukan ketika subyek memberikan ASI, memakaikan pakaian, dan aktifitas lainnya bersama bayi. Hal tersebut dilakukan dengan harapan mendapatkan keberkahan Al-Qur'an untuk optimalisasi tumbuh kembang otak anak. Hal ini sebagaimana berdasarkan penelitian otak, ahli pendidikan anak usia dini memilki keyakinan bahwa perkembangan intelektual yang paling cepat terjadi ialah sebelum usia lima tahun. Gagasan untuk meningkatkan perkembangan kognitif dengan menjadikan lingkungan rumah dan keluarga berkualitas dan bermanfaat (Morisson, 2012). Upaya mempendengarkan Al-Qur'an setiap saat ini menjadi pendidikan yang berkualitas dan bermanfaat bagi keluarga subyek.

Di usia 6 bulan, subyek sudah memperkenalkan huruf hijaiyah dengan membuat sendiri kumpulan huruf hijaiyah menggunakan kardus bekas dan kertas origami yang ditempel dengan ukuran besar agar mudah dilihat oleh anak. Setiap hari subyek selalu membunyikan huruf hijaiyah tersebut dengan acak guna menstimulasi indera. Penelitian sebelumnya menjelaskan bahwa bayi yang memiliki respon pasif pada otak dan pendengaran meningkat dengan adanya rangsangan visual simultan (Hyde, Jones, Porter, \& Flom, 2010). Hal ini membuktikan bahwa stimulasi visual memberikan pengaruh pada otak dan pendengaran bayi.

Stimulasi tersebut memberikan dampak efektif pada Hilya di usia 1 tahun ketika belum bisa bicara, anak dengan mudah mengingat kembali huruf hijaiyah dengan menunjuk bentuk huruf hijaiyah dengan benar. Pada saat anak berusia 2 tahun dan sudah bisa bicara, anak sudah bisa menebak huruf hijaiyah secara acak dengan membunyikannya. Hal ini dilakukan subyek untuk menstimulasi anak dan menuntun anak agar dapat membaca Al-Qur'an sejak dini. Ini merupakan langkah awal dalam menghafal Al-Qur'an yaitu mengenal huruf hijaiyah kemudian mampu membacanya dengan baik dan benar. 
Stimulasi Al-Qur'an pada usia 1 - 5 tahun

Saat anak usia 1 tahun dan belum bisa bicara, anak sudah bisa menunjuk huruf hijaiyah. Ketika subyek bertanya "sya mana sya? Shod mana shod?" anak menunjuk hurufnya dengan benar. Setelah usia 1 tahun dan anak sudah bisa berbicara, anak sudah bisa membunyikan huruf hijaiyah ketika subyek menunjuk tanda. Subyek menunjuk huruf "ini apa?" anak menjawab "Ba ba". Hilya mampu mengenal dan menghafalkan huruf hijaiyah selama 1 hingga 2 tahun dan menyelesaikan iqro' di usia 3 tahun. Setelah iqro' selesai, subyek melanjutkan targetnya dalam melancarkan bacaan Al-Qur'an anak dengan metode talaqqi bin nadzhor dimulai dari juz 30 .

Talaqqi bin nadzhor adalah pembacaan Al-Qur'an oleh Hilya dengan melihat mushaf Al-Qur'an yang disimak oleh subyek maupun suami subyek guna memperbaiki apabila terdapat bacaan yang kurang tepat. Hilya mampu menyelesaikan talaqqi ini dalam kurun waktu satu tahun. Setelah menyelesaikan talaqqi bin nadzhor, Hilya mulai menghafalkan Al-Qur'an pada usia 4 tahun dimulai dari juz belakang. Hilya sudah menghafal juz 30 karena sering di talqin (diperdengarkan) sejak bayi. Maka, Hilya mengawali hafalannya dari juz 29 ke depan.

Untuk pertama kali, Hilya hanya menghafal 3 baris ayat Al-Qur'an, kemudian meningkat menjadi setengah halaman, dan satu halaman per hafalan. Sebelum menghafalkan, Hilya membaca ayat yang hendak dihafal terlebih dahulu didepan subyek agar subyek dapat memastikan bacaan yang dihafalkan Hilya benar. Setelah itu, Hilya menghafalnya dalam aktifitas yang disenanginya. Terkadang, menghafalkan sambil bersepeda, bermain masak-masakan, dan kegiatan menyenangkan lainnya.
Setelah hafal, Hilya menyetorkan hafalannya pada subyek. Pada usia di bawah 5 tahun, kegiatan setor hafalan dilakukan oleh subyek sesuai keinginan Hilya. Terkadang, subyek harus mengikuti Hilya berlari, bersepeda, dan permainan lainnya untuk mendengarkan hafalan Hilya. Hilya termasuk anak yang memiliki kecerdasan dominan kinestetik. Hal ini dilakukan subyek karena tidak ingin merampas waktu bermain dan kesenangan anak namun tetap memasukkan pendidikan Al-Qur'an didalamnya.

Subyek tidak memberikan metode khusus dalam menghafal. Metode yang dilakukan subyek ialah mengajarkan anak untuk bisa membaca Al-Qur'an dengan benar terlebih dahulu agar anak mampu membaca Al-Qur'an mandiri, kemudian memulai menghafal diawali dari juz 30, mengkonsistenkan dengan 3 baris per hari tergantung dari mood anak atau tingkat kemudahan ayat. Berbagai metode yang digunakan dalam pembelajaran Al Quran membawa dampak akan kemudahan dalam mempelajarinya (Saifuddin \& Amalia, 2018)

Di usia 7 tahun, Hilya sudah konsisten menghafal 1 hari 1 halaman. Hal ini dikarenakan Hilya sudah terbiasa untuk menghafal setiap harinya. Hilya selesai mensetorkan 30 juz di usia 8 tahun 7 bulan dengan lama menghafal kurang lebih 4 tahun.

\section{Menggunakan Satu Mushaf Al-Qur'an}

Subyek memfasilitasi Al-Qur'an per juz agar anak bisa membawa Al-Qur'an kemana dan kapan saja tanpa merasa berat. Hal ini dikarenakan bentuk Al-Qur'an per juz tipis dan mudah untuk dibawa. Subyek memberikan mushaf tersebut dikarenakan paham dengan kinestetik anaknya yang senang menghafal dan memuroja'ah sambil bermain, berlari, dan aktifitas lain yang disenanginya. 
Ketika konsisten menggunakan satu jenis mushaf, penghafal Al-Qur'an mampu mengingat berbagai halaman dari mushaf yang ia gunakan, baik ayat-ayat tertentu, juz, atau awal dan akhir surat dalam AlQur'an. Dengan hanya menggunakan satu jenis mushaf, akan memantapkan hafalan anak dan menjadikannya lebih mampu untuk menyambung, menggabungkan, dan menyelsaikan halaman dengan baik, cepat, dan kuat (Qomariyah \& Irsyad, 2016).

\section{Jadwal Sehari-hari yang Diterapkan pada Anak}

Jadwal untuk Hilya sudah diberikan sejak usia 3 tahun, namun masih belum konsisten karena anak masih mengalami moody. Pada usia 5 tahun, subyek sudah mulai menerapkan jadwal yang disiplin tepatnya setelah mengikuti program Hafidz Indonesia RCTI tahun 2013. Subyek memberikan pembimbingan sesuai dengan fase usia anak, ketika usia masih dibawah 5 tahun, subyek masih mentoleransi keinginan anak, namun di usia 5 tahun subyek sudah mendisiplinkan dengan jadwal yang ditetapkan namun tetap penuh kelembutan dan kasih sayang. Ketika anak memasuki usia di atas 5 tahun dan hafalan sudah mulai banyak, jadwal muroja'ah pun lebih banyak diterapkan pada hari-hari anak dan subyek pun semakin tegas dalam memberikan pendidikan untuk disiplin.

Di usia 4 tahun, Hilya sudah dibiasakan bangun malam untuk shalat tahajjud sebelum subuh, minimal 2 rakaat tahajjud dan 1 rakaat witir, kemudian shalat subuh dilanjutkan ziyadah untuk menambah hafalan Al-Qur'an dimulai selesai shalat subuh, kurang lebih durasinya 1-2 jam. Ketika ziyadah selesai, anak kemudian memuroja'ah hafalan yang kemarin. Setelah itu istirahat di pagi hari untuk makan, mandi, dan waktu bebas dan dibiarkan tidur sebelum dzuhur mengikuti sunnah Rasulullah Shalallahu 'alayhi wa sallam.
Subyek tidak memberikan jadwal baku dengan berpaku waktu, namun hanya membuat target berapa banyak yang harus dihafal dan dimuroja'ah dalam sehari. Subyek bersifat fleksibel dalam mengatur waktu anak, yang terpenting adalah anak konsisten menghafal dan memuroja'ah dalam setiap waktunya dan anak senang melakukannya. Pola muroja'ahnya yang dilakukan Hilya ketika selesai ziyadah dilihat dari juz terjauh yang belum diulang. Subyek menggunakan pola muroja'ah FAMIBISYAUQIN. Pola muroja'ah ini mencakup surat surat Al-Qur'an yang dilakukan oleh salafushshalih. Hal ini dijalani supaya Hilya tahu awal dan akhir surat dalam Al-Qur'an.

\section{Dampak psikologis anak dalam menghafal Al-Qur'an sejak dini}

Berdasarkan penelitian yang dilakukan, Hilya merasa senang dan menikmati dirinya dengan segala aktifitasnya sebagai penghafal Al-Qur'an. Ketika wawancara bersama Hilya, peneliti melihat keteguhan seorang Hilya yang memiliki cita-cita besar ingin memberikan mahkota untuk orang tuanya kelak di Akhirat dengan hafalan Al-Qur'annya. Hal ini sebagaimana hadits riwayat Hakim 1/756, "Siapa yang menghafalkan AlQur'an, mengkajinya dan mengamalkannya, maka Allah akan memberikan mahkota bagi kedua orang tuanya dari cahaya yang terangnya seperti matahari. Dan kedua orang tuanya akan diberi dua pakaian yang tidak bisa dinilai dengan dunia. Kemudian kedua orang tuanya bertanya, "Mengapa saya sampai diberi pakaian semacam ini?" Lalu disampaikan kepadanya, "Disebabkan anakmu telah mengamalkan Al-Qur'an." (Al-Kamil, 2009). Cita-cita ini menjadi motivasi bagi Hilya saat ini untuk terus menjaga Al-Qur'an dalam dirinya 


\section{KESIMPULAN}

Berdasarkan penelitian tersebut dapat disimpulkan bahwa konsep pendidikan hafidz Qur'an yang diterapkan untuk anak usia dini tidak diterapkan secara instan, perlu proses yang membutuhkan kesabaran dan motivasi yang kuat dari orang tua. Orang tua perlu menjadi teladan yang baik bagi anak dan lebih dahulu menguatkan niat dan motivasi yang kuat agar tetap konsisten menerapkan pendidikan ini. Kemudian orang tua perlu menempatkan diri dan keluarga di lingkungan yang mendukung untuk anak dapat menghafal Al-Qur'an. Penerapan pendidikan Al-Qur'an dimulai sejak anak masih dalam kandungan dan diteruskan hingga akhir hayat. Orang tua harus membiasakan diri untuk banyak berinteraksi dengan Al-Qur'an baik membaca, mendengar, maupun menghafalkan sejak hamil guna menstimulasi anak sejak dalam kandungan. Ketika anak sudah diberikan pembiasaan sejak dalam kandungan, bayi, dan usia di atasnya maka anak akan mudah dalam menghafal Al-Qur'an. Hal ini dikarenakan usia dini merupakan tahap emas dimana orang tua penting untuk memberikan banyak bekal kebaikan dan fondasi bagi anak. Pendidikan hafidz Qur'an ini tidak menyalahi fitrah anak untuk bermain jika orang tua memfasilitasi kegiatan bermain yang tepat dan memberikan ruang serta waktu bagi anak untuk bermain dan menjalankan aktifitas menyenangkan sesuai keinginan anak namun tetap dalam koridor kebaikan.

\section{UCAPAN TERIMA KASIH}

Penulis ucapkan terima kasih kepada subyek penelitian dan keluarga, segenap civitas akademika Universitas Negeri Jakarta, dan seluruh tim jurnal obsesi Universitas Pahlawan Tuanku Tambusai

\section{DAFTAR PUSTAKA}

Agama, D. (2007). Al-Qur'an terjemah per kata. Jakarta: Departemen Agama Republik Indonesia.

Al-Kamil, A. A.-D. (2009). Cara Baru Menghafal Al-Qur'an. Klaten: Inas Media.

Bellieni, C. V. (2016). The Golden 1,000 Days. Journal General Practice, 4(1$3)$.

https://doi.org/https://doi.org/10.100 2/dev.20417

Eka Widi Susanti, Adelina Hasyim, Y. N. (2016). Faktor-Faktor Penyebab Orang Tua Tidak Menyekolahkan Anaknya di PAUD Fajar Desa Sumber Baru Kecamatan Seputih Banyak Kabupaten Lampung Tengah. Universitas Lampung. Lampung.

Hyde, D. C., Jones, B. L., Porter, C. L., \& Flom, R. (2010). Visual stimulation enhances auditory processing in 3month-old infants and adults. Developmental Psychobiology, 52(2), 181-189. https://doi.org/10.1002/dev.20417

Morisson, G. S. (2012). Dasar-dasar Pendidikan Anak Usia Dini. Jakarta: PT. Indeks.

Nawawi, I. (2010). Riyadhus Shalihin. Bandung: Penerbit Jabal.

Nawaz, N., \& Jahangir, P. D. S. F. (2015). Effects of Memorizing Quran by Heart (Hifz) On Later Academic Achievement. Journal of Islamic Studies and Culture, 3(1), 58-64. https://doi.org/10.15640/jisc.v3n1a8

Nazir, M. (2009). Metode Penelitian. Bogor: Ghalia Indonesia.

Papalia, D. E., Olds, S. W., \& Feldman, R. D. (2009). Human Development. America: Mc Graw Hill.

Qomariyah, N., \& Irsyad, M. (2016). Metode Cepat \& Mudah Agar Anak Hafal Al-Qur'an. Klaten: Semesta Hikmah. 
38 | Konsep Pendidikan Hafidz Qur'an pada Anak Usia Dini

Saifuddin, \& Amalia, I. . (2018). Pengelolaan Pembelajaran Alqur'an di RA. AWLADY: Jurnal Pendidikan Anak, 4(1), 119-128.

Suciati. (2015). the Impact of Prenatal Education Through Stimulating Quran' S Recitation on Child' S, $3(2)$.

Yani, I. E., \& Indrawati. (2014). Persepsi orangtua tentang paud ( studi yayasan bina insan mandiri kelurahan simpang baru kecamatan tampan kota pekanbaru). Jurnal Online Mahasiswa Bidang Ilmu Sosial Dan Ilmu Politik, 1(1). 